\title{
PADRÃO DE DISTRIBUIÇÃO E TAMANHO CORPORAL EM TRICHODACTYLIDAE E AEGLIDAE (DECAPODA)
}

\author{
Santos, S. ${ }^{1, *} ;$ Puli, G. ${ }^{1} \&$ Bartholomei-Santos, M.L. ${ }^{1}$ \\ ${ }^{1}$ Universidade Federal de Santa Maria (UFSM), PPG Biodiversidade Animal. \\ *Autor correspondente: sandro.santos@ufsm.br
}

\begin{abstract}
Padrões comuns de variação de tamanho corporal têm sido descritos para diversos grupos taxonômicos, tais como insetos, peixes, aves e mamíferos. Várias hipóteses surgiram para explicar as relações entre a área de distribuição geográfica e o tamanho corporal, mas suas causas subjacentes permanecem incertas para muitos grupos, e para outros, como os crustáceos, os estudos são praticamente inexistentes. Os crustáceos de água doce das famílias Trichodactylidae e Aeglidae são endêmicos da região neotropical da América do Sul, apresentando ampla diversidade de tamanho corporal. O objetivo deste estudo foi realizar uma análise exploratória inicial para verificar se há alguma relação entre tamanho corporal e padrão de distribuição de tricodactílideos e eglídeos na América do Sul. Foram realizadas análises de correlação de Pearson entre dados de latitudes da distribuição e medidas de tamanho máximo de Largura da Carapaça (LC) para tricodactilídeos, e comprimento da carapaça (CC) para eglídeos. A amplitude de distribuição para nove espécies de Trichodactylidae variou de $1^{\circ} \mathrm{S}$ a $30^{\circ} \mathrm{S}$ e para 28 espécies de Aeglidae variou de $20^{\circ} \mathrm{S}$ a $50^{\circ} \mathrm{S}$. Houve uma correlação negativa entre tamanho corporal (LC) e latitude para os tricodactilídeos ( $r=-0,7508 ; p=0.02)$, mas não para os eglídeos. Estes resultados indicam que animais de maior tamanho estão presentes nas menores latitudes enquanto animais menores seriam encontrados em latitudes maiores (mais ao sul do continente sulamericano), representando uma possível inversão na regra de Bergmann para os tricodactilídeos. Os eglídeos, por outro lado, aparentemente não seguem um padrão específico. Análises com maior tamanho amostral estão sendo realizadas com os dois grupos para confirmar estes resultados.
\end{abstract}

Palavras-chave: Anomura, Brachyura, crustáceos dulcícolas, Regra de Bergmann. 